\title{
The effects of light volleyball intervention programme in improving selected physical and psychological attributes of older adults in Hong Kong
}

\author{
Ka-Man Leung ${ }^{\text {a* }}$, Pak-Kwong Chung ${ }^{\mathrm{a}}$ and Martin S. Hagger ${ }^{\mathrm{b}, \mathrm{c}}$ \\ ${ }^{a}$ Department of Physical Education, Hong Kong Baptist University, Kowloon Tong, Kowloon, Hong \\ Kong; ${ }^{b}$ School of Psychology and Speech Pathology, Curtin University, Bentley, Australia; ${ }^{c}$ Faculty of \\ Sport and Health Sciences, University of Jyvaskyla, Jyvaskyla, Finland
}

(Received 1 September 2017; accepted 2 April 2018)

\begin{abstract}
Previous research has demonstrated improvements in health outcomes through participation in light volleyball (LVB) among older adults in China (He, 2009). This study examined the effects of a 15-week LVB intervention programme on physical and psychological attributes among older adults in Hong Kong. Participants $(N=78)$ aged $\geq 60$ years were assigned to one of the three groups: intervention (LVB), comparison [rouliqiu (RLQ)], and control groups (CGs). Participants completed functional fitness measures and physical activity enjoyment questionnaire before and after the intervention. Results revealed significant improvements in agility, cardiovascular endurance, upper and lower extremity muscle strength, and physical activity enjoyment among participants in the LVB group compared to the CG group. Participants in the LVB group also demonstrated greater cardiovascular endurance, upper extremity muscle strength, and physical activity enjoyment than participants in the RLQ group. Health practitioners may consider LVB as an adapted physical activity intervention to promote health outcomes in older adults.
\end{abstract}

Keywords: Chinese; enjoyment; functional fitness; older adults; physical activity

\section{Introduction}

The population in Hong Kong is ageing. Recent population census data predict that older adults aged 45 and older will number 4.40 million by 2031 and 4.82 million by 2041, respectively (Census and Statistics Department, HKSAR, 2012). In addition, there will be 2.16 million older adults aged 65 or above by 2031, and this figure will rise further to 2.56 million by 2041 . The ageing populating presents substantive problems for population health and health-care services. Significant consequences of an ageing population, for example, are reductions in the working-age population and increasing fiscal pressure on health-care, social welfare, and other services for older adults. In addition, high rates of overweight and obesity are endemic in this population (Bouaziz, Schmitt, Kaltenbach, Geny, \& Vogel, 2015; World Health Organization, 2011). Compounding this problem, Hong Kong adults to not participate in sufficient physical activity to confer health benefits. A territory-wide physical fitness test revealed that fewer than $30 \%$ of adults aged 40-59 years, and older adults aged 60-69 years, participated in sufficient physical activity and almost one of every two adults was classified as sedentary (Sports Commission of Hong Kong SAR Government, 2012). The Sports Commission of the Hong Kong Special Administrative Region (SAR) Government (2012) suggested substantive human cost and financial losses

*Corresponding author. Email: kmleung@hkbu.edu.hk 
would result from the inactive lifestyle of the Hong Kong population. Among numerous initiatives proposed to address the aforementioned challenges, the Hong Kong government has recommended an active ageing initiative (Steering Committee on Population Policy, HKSAR, 2014).

Promoting physical activity among older adults presents unique challenges. Research has indicated substantive age-related degradation in tests of upper and lower extremity muscle strength and flexibility, agility and dynamic balance, and aerobic endurance (Chung, Zhao, Liu, \& Quach, 2016). Significantly, the rate of degradation ranged up to $200 \%$. Therefore, in order to promote physical activity in the ageing population and prevent age-related fitness degradation, it is important to develop adapted physical activity intervention programmes among the older adults in Hong Kong.

Among different types of sports or physical activity, light volleyball (LVB) is a new sport modified from traditional volleyball that may help reduce fitness-related degradation among older adults. In contrast to traditional volleyball, LVB uses a lighter weight (LVB $150 \mathrm{~g}$ vs. traditional volleyball $250 \mathrm{~g}$ ) and bigger sized (LVB $80-83 \mathrm{~cm}$ in circumference vs. traditional volleyball $65-67 \mathrm{~cm}$ ) ball. The LVB ball thus travels in the air in a lower velocity and for a longer time, which increases the rally time between players during the games. It also makes LVB game more accessible to those with ageing-associated degradation. In addition, the LVB playing court is a standardised badminton court, which is smaller than a standard volleyball court. The smaller court enables the promotion of LVB in sport facilities that normally have limited space in Hong Kong. LVB is relatively prevalent as a physical activity for older adults in China (Sun, 2010). Studies in China have indicated that older adults gain physical and psychological health benefits from regular practice with LVB (Chen, 2004; He, 2009). However, some limitations were found in these studies. For example, the methods used to measure the components of fitness were not clearly stated, and effects were not compared to a control or comparison group.

In response to the increasing popularity of LVB in older adults, and the priority of assigning resources to the prevention of age-related fitness degradation in Hong Kong (Census and Statistics Department, HKSAR, 2012), the present study aimed to investigate the effectiveness of an LVB intervention on physical and psychological health attributes among older adults in Hong Kong. Specifically, we adopted a controlled design to evaluate the effectiveness of the LVB intervention on health outcomes against a comparison group receiving an alternative modified form of physical activity, rouliqiu (RLQ), and a no intervention control group (CG). This design addresses some of the limitations of previous studies aiming to evaluate the effectiveness of LVB activities on health outcomes in older adults. We hypothesised that the LVB and RLQ interventions would produce significant increases in selected physical and psychological health attributes compared with the CG. We expected the LVB intervention to be at least as effective as the RLQ intervention in producing health outcomes in older adults. Our study represents the first attempt to test the effectiveness of an LVB intervention on improving selected physical and psychological attributes in older adults in Hong Kong. We also expected our study would provide important insight into the role of LVB in promoting health-related outcomes that link to prevention of chronic diseases and premature death among older adults in Hong Kong. It may also inform resource allocation of practitioners and policymakers in the promotion of active ageing in Hong Kong. Finally, the results of present study may also provide evidence-based information to other countries for the promotion of physical activity among older adults.

\section{Methods}

\section{Design and participants}

This study adopted non-randomised intervention, pre-posttest design with intervention group (LVB group), reference group (RLQ group), and CG comparison in a group of Chinese older 
adults in Hong Kong. A comparison of results of selected functional fitness tests (i.e. chair stand (CS) test, arm curl (AC) test, chair sit and reach test, back scratch (BS) test, 8-foot up-and-go (UG) test, 2-minute step test (ST), body mass index (BMI) measure, and handgrip (HG) test) and psychological attribute (physical activity enjoyment) were made between the above groups. Prior to the data collection, an approval was received from the university Committee on the Use of Human and Animal Subjects in research. Participants aged 60 years and older were recruited from four elderly centres in Hong Kong. Recruitment process took place through a recruitment talk offered by the research team and by advertisements posted in the local elderly centres. An initial information session was delivered to groups of eligible older adults to provide them with details of the intervention, e.g. aims, procedures, and expectations. Inclusion criteria for participants were (a) aged over 60 years; (b) living in the community independently; (c) apparently healthy; and (d) not having participation in a structured physical activity programme for two years preceding the study. Older adults with steady hypertension (160/ $90 \mathrm{mmHg}$ or above), arthritis, and neurological disorders were excluded from the study.

We computed a projected sample size using a statistical power analysis by $\mathrm{G}^{*}$ power (v. 3.1.9.2; Faul, Erdfelder, Lang, \& Buchner, 2007). The analysis was based on a large effect size $\left(\eta^{2}=.918\right)$ from a previous study showing a large effect of RLQ training, the closest training programme to the LVB programme used in the current study, on functional fitness attributes in older adults (Lam, 2010). We also assumed $80 \%$ power and set alpha at .05. The analysis indicated that a total sample of 12 per group was required. We therefore aimed to recruit 18 participants per group (LVB, RLQ, CG) taking into account an expected 35\% expected dropout rate (Farrance, Tsofliou, \& Clark, 2016). All participants received form providing a brief description of the study and were then asked to provide informed consent by signing a consent form. Participants were advised of their confidentiality of personal data and informed that they could voluntarily withdraw from the project at any time without prejudice. Data collection was conducted in person by a research assistant and trained student helpers. Participants received a HK\$50 supermarket cash voucher as incentive for their participation.

\section{Measures}

Participants received measures of physical and psychological attributes before and after intervention. Only participants that fulfilled at least $80 \%$ attendance to the LVB and RLQ intervention programmes (Picorelli, Pereira, Pereira, Felício, \& Sherrington, 2014) received posttest measures. Participants' physical attributes were measured using the Senior Fitness Test Manual (Rikli \& Jones, 2013). The tests consist of the following seven items: CS test (lower body strength), AC test (upper body strength), chair sit and reach test (lower body flexibility), BS (upper body flexibility), 8-foot UG test (agility and balance), 2-minute ST (aerobic endurance), and body mass index (BMI; $\mathrm{kg} / \mathrm{m}^{2}$, body composition). Full details of the tests are presented in Appendix 1. These tests were found to be reliable with intra-class correlations ranging between .80 and .98 for participants in trials. Validity was established through content, construct, and criterion-related analyses, including comparing senior fitness test scores with other "gold standard" measures, such as treadmill $\mathrm{VO}_{2}$ testing (Rikli \& Jones, 1999). The HG test (forearm strength), a common physical fitness test, was also added to the test items.

We also measured participants' physical activity enjoyment using Raedeke's (2007) shortened version of Physical Activity Enjoyment Scale (PACES) (Kendzierski \& De Carlo, 1991). The scale comprised eight items measuring general exercise enjoyment (trait enjoyment; "I dislike it") and enjoyment of exercise at any given moment (state enjoyment; "I am very absorbed in this activity"). Responses were provided on 7-point Likert scales ranging from 1 (I enjoy it) to 7 (I hate it). 


\section{Intervention}

The intervention programmes were delivered from November to March 2016 by registered coaches and assistant coaches from the Light Volleyball Association of Hong Kong and the Hong Kong Rouliqiu Association, respectively. The volume (frequency and duration of sessions) of both intervention programmes was standardised. Each programme consisted of 30 training sessions, with 2 sessions per week and 90 minutes per session. Each session began with 10 minutes warm-up and concluded with 5-minute cool-down and stretching. The duration of intervention is consistent with the recommendation of U.S. Department of Health and Human Services Centers for Medicare and Medicaid Services (2003), which states that health benefits of physical activity in older adults can be seen as early as 1-3 months after initiation of a physical activity programme. The programme was designed by the lead author, a specialist in physical education and health promotion and a former member of the Hong Kong volleyball team.

RLQ is a sport that combines elements of Tai Chi and badminton. There are many similarities between LVB and RLQ, so RLQ was a good candidate for the sport in the CG in the current study. They are both adapted forms of physical activity that can be played on a badminton court, and use dominant arm movement to strike the ball. After interventions, participants were expected to have a better understanding of as well as perform a set of basic skills that facilitate their enjoyments of participations in the respective sport. Details of the intervention programsme are presented in Appendix 2.

\section{Procedure}

At the first testing session prior to the physical measures (pretest), participants completed the PACES questionnaire and some socio-demographic questions. After that, participants started with measures of height, weight, and percentage body fat using a Tanita machine (model: BC418). Participants then took the fitness tests in a standardised order (CS test; HG test; BS test; 8-foot UG test; AC test; chair sit and reach test; 2-minute ST) to maximise recovery and to minimise the level of fatigue. The intervention began in the second week. Prior to the final week of the intervention (15th week), participants completed posttest measures using identical procedures to the pretest. During the intervention, the CG participants were instructed to maintain their normal daily activity (see the flow diagram of the study data collection protocol presented in Figure 1).

\section{Data analysis}

Data were analysed using the statistical package for social science (SPSS v. 24.0).

A multivariate analysis of covariance (MANCOVA) was conducted to examine group effects on measures of physical attributes. In this analysis, group (i.e. LVB group, RLQ group, and CG) was the independent variable while the posttest score of measures on physical attributes were the dependent variables. Pretest scores of each outcome measure of physical attributes were entered as covariates. Statistically significant multivariate effects from the MANCOVA were followed up by separate univariate ANCOVAs to test for intervention effects on each dependent variable. Differences in physical activity enjoyment across the three groups were tested using an ANCOVA with group as the independent variable, posttest enjoyment scores as the dependent variable, and pretest values as the covariates. Subsequently, differences between groups were analysed through pairwise comparisons with Bonferroni correction.

\section{Results}

At the commencement of the intervention programme, seventy-eight participants were recruited and completed the pretest measures (LVB group, $n=25$; RLQ group, $n=30 ; \mathrm{CG}, n=23$ ). Fifteen 


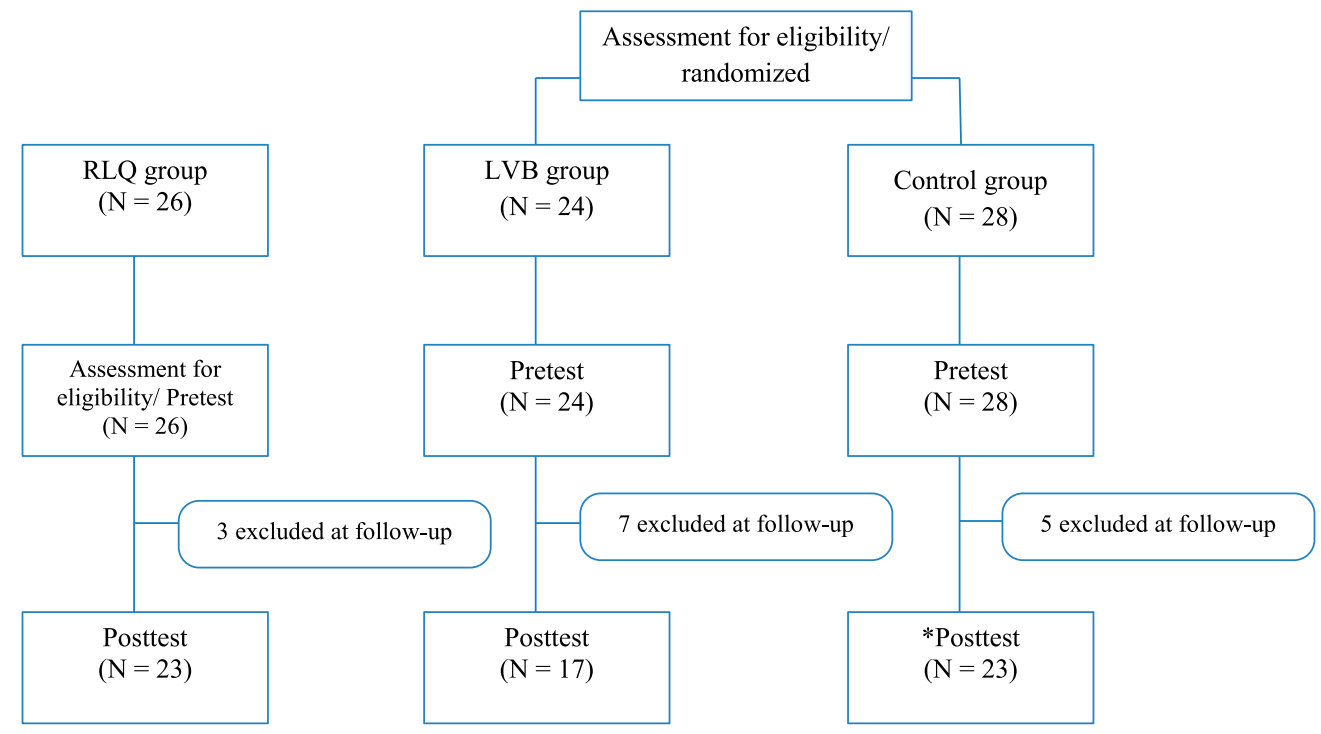

Figure 1. Flowchart of data collection through the study.

* One participant was excluded from the data analysis for missing four fitness tests after the intervention.

participants were excluded from posttest measures due to drop out or insufficient attendance rate on completion of the intervention. One participant missed four fitness tests and was also excluded. Finally, 62 participants (LVB group, $n=17$; RLQ group, $n=23$; $\mathrm{CG}, n=22$ ) (retention rate $80 \%$ ) were included in data analysis. No significant group differences were found for the pretest scores of all outcome measures (CS test, $F(2,59)=.48, p=.621$, partial $\eta^{2}=.02$; AC, $F(2,59)$ $=.24, p=.101$, partial $\eta^{2}=.07$; chair sit and reach test, $F(2,59)=9.11, p=.408$, partial $\eta^{2}=.03$; BS, $F(2,59)=2.44, p=.096$, partial $\eta^{2}=.08$; UG test, $F(2,59)=0.99, p=.374$, partial $\eta^{2}=.03$; HG, $F(2,59)=.67, p=.517$, partial $\eta^{2}=.02$; Body Mass Index, $F(2,59)=2.32$, $p=.107$, partial $\eta^{2}=.07$; PACERS, $F(2,59)=.21, p=.810$, partial $\left.\eta^{2}=.007\right)$, with the exception of the ST, $\left(F(2,59)=3.16, p=.050\right.$; partial $\left.\eta^{2}=.10\right)$. The socio-demographic characteristics of participants are presented in Table 1.

\section{Physical attributes}

Means and standard deviations of physical and psychological measures of pretest and posttest by groups are presented in Table 2. A one-way MANCOVA was performed to test for posttest group differences on physical attribute scores (i.e. CS test, AC test, chair sit, and reach test, BS, 8-foot UG test, 2-minute ST, BMI, and HG) with pretest scores as covariates. ${ }^{1}$ We found a significant group difference on posttest scores, $F(16,84)=4.92, p=.001$, partial $\eta^{2}=.47$. Follow-up univariate ANCOVAs revealed significant group differences on posttest values for the CS test $(F(2,58)$ $=15.16, p=.001$, partial $\left.\eta^{2}=.34\right), 2$-minute ST $\left(F(2,58)=13.29, p=.001\right.$, partial $\left.\eta^{2}=.31\right)$, 8 -foot UG test $\left(F(2,58)=14.25, p=.001\right.$, partial $\left.\eta^{2}=.33\right)$, and HG test $(F(2,58)=13.48$, $p=.001$, partial $\eta^{2}=.32$ ). Bonferroni pairwise comparisons showed that participants in the LVB and RLQ groups performed better on the CS (LVB group, $M=17.83$, RLQ group, $M=$ 18.32) and 8-foot UG test (LVB group, $M=5.43$, RLQ group, $M=5.48$ ) groups than participants in the CG group (CS test, $M=12.80, p=.001 ; 8$-foot UG test, $M=6.80, p=.001$ ).

Moreover, participants in the LVB performed better on the ST (LVB group, $M=100.73$, $p=.001$ ) and HG test (LVB group, $M=23.52 \mathrm{kgf}, p=.001$ ) than participants in the RLQ (ST, 
Table 1. Socio-demographic characteristics of participants.

\begin{tabular}{|c|c|c|c|}
\hline Age $($ mean \pm SD) & $\begin{array}{c}\text { LVB } \\
72.00(1.52)\end{array}$ & $\begin{array}{c}\text { RLQ } \\
72.04(1.75)\end{array}$ & $\begin{array}{c}\text { Control } \\
75.05(1.56)\end{array}$ \\
\hline \multicolumn{4}{|l|}{ Gender } \\
\hline Female & 9 & 22 & 18 \\
\hline Male & 8 & 1 & 4 \\
\hline \multicolumn{4}{|l|}{ Occupation } \\
\hline Full time job & 0 & 1 & 0 \\
\hline Housewife & 2 & 7 & 5 \\
\hline Retired & 15 & 15 & 17 \\
\hline \multicolumn{4}{|l|}{ Education level } \\
\hline No education & 0 & 2 & 10 \\
\hline Primary education & 7 & 15 & 6 \\
\hline Secondary education & 9 & 5 & 4 \\
\hline Tertiary education & 1 & 0 & 2 \\
\hline Body mass index $\left(\mathrm{kg} / \mathrm{m}^{2}\right)$ & $23.94(2.91)$ & $22.70(3.65)$ & $23.19(3.14)$ \\
\hline
\end{tabular}

Note: LVB, light volleyball group; RLQ group, rouliqiu group; CG, control group.

$M=83.33$; HG test, $M=19.82 \mathrm{kgf}$ ) and CG group (ST, $M=77.59$, HG test, $M=19.04 \mathrm{kgf}$ ). The impact of the interventions was further clarified by examining the unadjusted mean pretest and posttest scores. The unadjusted means are presented in Table 2.

No significant group differences were found for the AC test $(F(2,58)=2.67, p=.080$, partial $\left.\eta^{2}=.08\right)$ chair sit and reach test $\left(F(2,58)=.08, p=.99 \mathrm{x}\right.$, partial $\left.\eta^{2}=.001\right)$, and BS test $\left(F(2,58)=.76, p=.47 x\right.$, partial $\left.\eta^{2}=.03\right)$.

\section{Enjoyment}

A one-way ANCOVA was also performed to compare the posttest means of perceived enjoyment scores in LVB group, RLQ group, and CG, with pretest scores as covariates. Significant group difference on posttest scores was found, $F(2,58)=7.41, p=.001$, partial $\eta^{2}=.20$. Participants in the LVB showed higher enjoyment (LVB group, $M=50.82$ ) than participants in the RLQ $(M=45.26, p=.03)$ and CG group $(M=42.64, p=.001)$.

\section{Discussion}

Given the social implications of an ageing population, benefits of doing physical activity, and health problems related to low levels of physical activity among the older adults in Hong Kong, the current study aims to examine the effects of a 15-week LVB intervention programmes on physical outcomes and enjoyment outcomes using a non-randomised intervention design. Findings indicated that the LVB intervention was associated with greater scores on five attributes: lower extremity muscle strength, agility and dynamic balance, aerobic endurance, upper extremity muscle strength, and physical activity enjoyment, relative to controls. In addition, the LVB programme was related to greater aerobic endurance, upper extremity muscle strength, and physical activity enjoyment relative to the RLQ programme.

To our knowledge, this is the first study to our knowledge to explore the impact of LVB, a new adapted sport, on physical and psychological attributes among older adults. A recent meta-analysis of the effectiveness of interventions designed to increase physical activity among older adults found an overall small effect size of physical activity interventions $(d=.18$; Chase, 2015). The effect size of the current intervention compared to the CG exceeded this effect size. Possible 
Table 2. Means and standard deviations for measures in groups at pretest and posttest.

\begin{tabular}{|c|c|c|c|c|c|c|c|c|c|}
\hline \multirow{2}{*}{ Measures } & \multicolumn{2}{|c|}{$\mathrm{CG}(N=22)$} & \multicolumn{2}{|c|}{$\operatorname{RLQ}(N=23)$} & \multicolumn{2}{|c|}{$\operatorname{LVB}(N=17)$} & \multirow{2}{*}{$F$} & \multicolumn{2}{|c|}{ Mean difference } \\
\hline & Pretest & Posttest & Pretest & Posttest & Pretest & Posttest & & $\mathrm{LVB}-\mathrm{CG}$ & LVB - RLQ \\
\hline Chair stand test (frequency) & $12.10(4.05)$ & 12.80 & $11.96(3.17)$ & 18.32 & $13.00(2.98)$ & 17.83 & $15.16^{* *}$ & $5.02 * *$ & -0.49 \\
\hline Arm curl (frequency) & $12.15(3.53)$ & 14.30 & $14.78(4.10)$ & 17.35 & $13.94(3.25)$ & 16.50 & 2.67 & 2.20 & -0.85 \\
\hline Chair sit and reach test $(\mathrm{cm})$ & $-.60(9.52)$ & 0.84 & $3.30(7.46)$ & 0.83 & $-0.05(8.64)$ & 1.03 & 0.08 & 0.19 & 0.19 \\
\hline Back scratch (cm) & $-3.64(6.46)$ & -1.04 & $-0.14(6.84)$ & 0.52 & $-0.35(7.25)$ & 0.03 & 0.76 & 1.06 & -0.49 \\
\hline Up-and-go test (s) & $6.82(1.37)$ & 6.80 & $6.44(1.09)$ & 5.48 & $6.12(1.63)$ & 5.43 & $14.25 * *$ & $-1.37 * *$ & -0.05 \\
\hline Step test (frequency) & $74.40(15.46)$ & 77.59 & $78.17(17.85)$ & 83.33 & $63.88(20.51)$ & 100.73 & $13.29 * *$ & $23.15 * *$ & $17.40 * *$ \\
\hline Handgrip & $22.37(5.16)$ & 19.04 & $20.93(4.62)$ & 19.82 & $21.35(6.29)$ & 23.52 & $13.48 * *$ & $4.48 * *$ & $3.70 * *$ \\
\hline Body mass index $\left(\mathrm{kg} / \mathrm{m}^{2}\right)$ & $23.94(2.91)$ & 23.34 & $22.70(3.65)$ & 23.04 & $23.19(3.14)$ & 23.48 & 1.96 & 0.14 & 0.44 \\
\hline PACERS (score) & $45.10(10.60)$ & 42.64 & $47.35(6.70)$ & 45.26 & $46.12(9.45)$ & 50.82 & $7.41 * *$ & $8.18 * *$ & $5.56^{*}$ \\
\hline
\end{tabular}

Note: $* p<.05 ; * * p .01 * * * p<.001 ; \mathrm{LVB}$, light volleyball group; RLQ, rouliqiu group; CG, control group. The posttest scores were adjusted via ANCOVA for difference in the pretest

scores. Other than of the pretest scores of all physical attributes, no other potential confounding variables such as health condition were entered as covariates in the data analysis. 
reasons for the larger effect included our use of standardised fitness measurements, a centre-based intervention, group-based intervention, and use of audio-visual media (i.e. a professional instructor-led in the intervention). Importantly, rates of adherence rate to the intervention programme were high: about $80 \%$ of participants attended the intervention sessions and completed both pretest and posttest measures. This is far higher than the expected 50\% adherence rate suggested by Dishman (2001) and higher than the $69.1 \%$ adherence rate from the systematic review conducted by Farrance et al. (2016). This might relate to the quality of intervention programme (i.e. well organised and delivered by professional coaches), social connectedness in playing team sports (i.e. LVB and RLQ), participants' perceived health benefits, constructive instructor behaviours, and accessible features of the programme design (including location of centre, financial cost, the structure and content of the class).

\section{Improvements in physical health}

It is not surprising that participants in the current study improved in upper and lower body strength and agility because similar to traditional volleyball, playing LVB involves considerable lower and upper body movements. Although the rules and regulations are less strict in LVB, it still involves vigorous movements of the hip, knee, and abdomen, as well as the performance of lateral (side-to-side) movements or even jumping (Hedrick, 2007). In addition, LVB requires arm and shoulder movements to strike the ball and perform the service. More than half of total game time is involved in dynamic offensive and defensive movement (spiking and blocking), which requires upper body strength, including shoulder, elbow, and wrist strength (Hedrick, 2007). Additionally, LVB is an interactive game in which players are required to accelerate, decelerate, and move in different directions. Agility and dynamic balance are therefore important. The duration and frequency of the LVB programme in the current study exceeded World Health Organization (2011) recommendations that older adults should participate in 150 minutes of moderateintensity aerobic physical activity in a week (Bouaziz et al., 2016, 2017). This likely contributed to improvements in participants' aerobic endurance.

In addition, we also found that the LVB intervention programme is more effective than the RLQ intervention programme in improving aerobic endurance and upper extremity muscle strength of the participants. Lam (2010) conducted a similar RLQ training programme and found no improvements on functional health and health-related quality of life among older adults in Hong Kong. A reason for achieving greater effects from the LVB programme over the RLQ programme may relate to the content of the activities. For example, the RLQ programme contains a highly structured set routine in which movement pace and intensity are planned and stable. In contrast, LVB is conducted in the context of a rapidly changing game scenario requiring dynamic adjustment to game conditions that are not planned or expected. These proactive and multiple movements in LVB may give participants a more challenging and less predictable environment that offers greater capacity to develop aerobic endurance and upper extremity muscle strength compared to RLQ.

\section{Improvements in enjoyment}

Findings from psychological measures indicated that LVB participants had higher physical activity enjoyment compared to RLQ and CG participants. Our results are consistent with previous studies using another adapted version of volleyball, water volleyball, in older adults (Maine, 2017). A possible reason for this is the increased interaction and team component of the LVB programme. The RLQ activity requires participants to exercise in a routine on their own, while the LVB activity requires cooperation and communication with others. It is also 
possible that participants gained a sense of greater enjoyment by experiencing competence (Pihu, Hein, Koka, \& Hagger, 2008), physical self-esteem (Hagger \& Stevenson, 2010), and developing positive habits (Hamilton, Kirkpatrick, Rebar, \& Hagger, 2017).

\section{Limitations and recommendations for future research}

The current study has some limitations. First, the participants are mainly females (80\%) which restricted gender comparisons. However, Chase's (2015) meta-analysis of physical activity interventions found similar effects interventions on physical activity regardless of the ratio of males and females in study samples. Second, participants in the current study were not randomly assigned into the groups due to residential locations as well as availability of facilities in the four partnered elderly centres. Therefore, the RLQ programme had to be implemented in a separate elderly centre. Third, no further follow-up assessment was conducted to monitor maintenance and changes of physical and psychological measures.

Future studies could be conducted to resolve the above limitations. Studies should consider recruiting samples with equal representation of males and females, random assignment of participants into intervention and CGs, and include further post-intervention follow-up assessments. Future research may also make use of a combination of cognitive and behavioural intervention strategies to promote physical activity (Chase, 2015; Farrance et al., 2016). Also, to gain a deeper understanding about the impact of LVB to older adults' health, researchers may adopt a mixed-method approach combining quantitative and qualitative methods to comprehensively examine the training effects of LVB programmes and the experiences of participants in the programmes (c.f., Hardcastle, Tye, Glassey, \& Hagger, 2015). This would be important for establishing the experiential aspects of LVB and accounting for the usability and feasibility of rolling out the intervention in a community-wide setting.

\section{Conclusion}

The 15-week LVB intervention programme resulted in significant improvements on functional fitness as well as physical activity enjoyment in the older adults. The LVB programme demonstrated promising effects, which could be further developed as a community-based modified physical activity programme suitable for older adults. Results also suggest that LVB can be an integral part of future initiatives to promote active ageing by the Hong Kong Government that LVB. The Hong Kong government is recommended to organise and promote LVB programme regularly in community centres, increase subsidies to the Hong Kong Light Volleyball Association, and include LVB in the Leisure and Cultural Services Department's community recreation and sport programmes. Finally, the results of present study may also provide evidence-based information for other countries to promote physical activity in older adults.

\section{Acknowledgements}

The authors gratefully acknowledge that support from the Hong Kong Light Volleyball Association Ltd. and the partnered elderly centres.

\section{Funding}

This work was supported by Knowledge Transfer Partnership Seed Fund, Hong Kong Baptist University: [Grant Number KTP/042/MAY2015]. 


\section{Note}

1. Preliminary screening of data revealed no problems due to missing data, outlier, and multivariate normality. Homogeneity of covariance matrices were supported using Box's M (Box's $M=99.77$, $p=.254$ ). Homogeneity of regressions (insignificant interaction between groups and posttest scores), multicollinearity (Variance Inflation Factor (VIF) less than 10), and linear relationship between covariates (i.e. pretests) and the posttests (significant Bartlett's test of sphericity) were supported.

\section{References}

Bouaziz, W., Lang, P. O., Schmitt, E., Kaltenbach, G., Geny, B., \& Vogel, T. (2016). Health benefits of multicomponent training programmes in seniors: A systematic review. International Journal of Clinical Practice, 70(7), 520-536.

Bouaziz, W., Schmitt, E., Kaltenbach, G., Geny, B., \& Vogel, T. (2015). Health benefits of endurance training alone or combined with diet for obese patients over 60: A review. The International Journal of Clinical Practice, 69, 1032-1049. doi:10.1111/ijcp.12648.

Bouaziz, W., Vogel, T., Schmitt, E., Kaltenbach, G., Geny, B., \& Lang, P. O. (2017). Health benefits of aerobic training programs in adults aged 70 and over: A systematic review. Archives of Gerontology and Geriatrics, 69, 110-127. https://doi.org/10.1016/j.archger.2016.10.012

Census and Statistics Department, HKSAR. (2012). Hong Kong population projections 2012-2041. Retrieved from http://www.censtatd.gov.hk/hkstat/sub/sp190.jsp?productCode=B1120015

Chase, J. A. D. (2015). Interventions to increase physical activity among older adults: A meta-analysis. The Gerontologist, 55(4), 706-718.

Chen, H. C. (2004). The training value about the gas volleyball exercise for the aged. Journal of MinJiang University, 25(5), 117-119.

Chung, P. K., Zhao, Y., Liu, J. D., \& Quach, B. (2016). Functional fitness norms for community-dwelling older adults in Hong Kong. Archives of Gerontology and Geriatrics, 65, 54-62.

Dishman, R. K. (2001). The problem of exercise adherence: Fighting sloth in nations with market economies. Quest (grand Rapids, Mich), 53(3), 279-294.

Farrance, C., Tsofliou, F., \& Clark, C. (2016). Review article: Adherence to community based group exercise interventions for older people: A mixed-methods systematic review. Preventive Medicine, 87, 155-166.

Faul, F., Erdfelder, E., Lang, A.-G., \& Buchner, A. (2007). G*Power 3: A flexible statistical power analysis program for the social, behavioral, and biomedical sciences. Behavior Research Methods, 39, 175-191.

Hagger, M. S., \& Stevenson, A. (2010). Social physique anxiety and physical self-esteem: Gender and age effects. Psychology \& Health, 25, 89-110.

Hamilton, K., Kirkpatrick, A., Rebar, A., \& Hagger, M. S. (2017). Child sun safety: Application of an integrated behavior change model. Health Psychology, 36, 916-926.

Hardcastle, S. J., Tye, M., Glassey, R., \& Hagger, M. S. (2015). Exploring the perceived effectiveness of a life skills development program for high-performance athletes. Psychology of Sport and Exercise, 16, $139-149$.

He, Y. (2009). On gas volleyball's fitness value and its promotion. Sport Science and Technology, 30(2), 77 85.

Hedrick, A. (2007). Training for high level performance in women's collegiate volleyball: Part I training requirements. Strength and Conditioning Journal, 29(6), 50-53.

Kendzierski, D., \& De Carlo, K. L. (1991). Physical activity enjoyment scale: Two validation studies. Journal of Sport and Exercise Psychology, 13, 50-64.

Lam, H. S. (2010). The effects of Rouliqiu training on physical functional health and health related quality of life of elderly in Hong Kong (Master's thesis). Hong Kong Baptist University, Hong Kong.

Maine, B. (2017). UNE U-ExCEL program gets older adults moving with retirement community volleyball match. Retrieved from https://www.une.edu/news/2017/une-u-excel-program-gets-older-adultsmoving-retirement-community-volleyball-match

Picorelli, A. M. A., Pereira, L. S. M., Pereira, D. S., Felício, D., \& Sherrington, C. (2014). Adherence to exercise programs for older people is influenced by program characteristics and personal factors: A systematic review. Journal of Physiotherapy, 60(3), 151-156.

Pihu, M., Hein, V., Koka, A., \& Hagger, M. S. (2008). How students' perceptions of teacher's autonomysupportive behaviours affect physical activity behaviour: An application of trans-contextual model. European Journal of Sport Science, 8, 193-204. 
Raedeke, T. D. (2007). The Relationship between enjoyment and affective responses to exercise. Journal of Applied Sport Psychology, 19(1), 105-115.

Rikli, R. E., \& Jones, C. J. (1999). Development and validation of a functional fitness test for communityresiding older adults. Journal of Aging and Physical Activity, 7, 129-161.

Rikli, R. E., \& Jones, C. J. (2013). Senior fitness test manual. Champaign, IL: Human Kinetics.

Sports Commission of Hong Kong SAR Government. (2012). Healthy exercise for all campaign - The Physical Fitness Test for the Community. Retrieved from http://www.lcsd.gov.hk/en/healthy/physical_ fitness test/common/physical fitness test/download/SummaryReport en.pdf

Steering Committee on Population Policy, the Government of the Hong Kong Administrative Region. (2014). Public engagement exercise on population policy. Retrieved from http://www.hkpopulation. gov.hk/public_engagement/pdf/PEEPP_eng_lowres.pdf

Sun. (2010). Sociological analysis of the rise of gas volleyball in China. Journal of Anhui Sport s Science, 31 (6), $10-12$.

U.S. Department of Health and Human Services Centers for Medicare and Medicaid Services. (2003). Exercise programs for older adults: A systematic review and meta-analysis. Retrieved from http:// www.rand.org/pubs/reprints/RP1257.html

World Health Organization. (2011). Global Recommendations on Physical Activity for Health: 65 years and above. Retrieved from http://www.who.int/dietphysicalactivity/physical-activity-recommendations65years.pdf

\section{Appendix 1. Measures}

CS test reflected participant's lower body strength, involve counting the number of times a participant rise to a full stand from seating position in 30 seconds ( 1 trial); AC is a measure of upper body strength, involve counting the number of time a participant perform full $\mathrm{AC}$ motion on their dominant arm (5 $\mathrm{lbs}$ for female and $8 \mathrm{lbs}$ for male) in 30 seconds (1 trial). Chair sit and reach test (CR) modified the traditional (floor) sit and reach test ( 2 trials), measuring the lower body flexibility while BS measures the upper body flexibility ( 2 trials). In both CR and BS, participants need to perform the test on their most comfortable limb. Eight-foot UG test involves getting out of chair, walk towards the cone located 8-foot away and return to the chair by go around the cone ( 2 trials). It determines participants' agility and dynamic balance. The last test of the Senior Fitness Test Manual applied in the study was 2-minute ST which is a test of aerobic endurance (1 trial). Participant stepped as many times as possible in 2 minutes on the same spot and the more step counts would indicate a higher level of aerobic endurance. Recently in Hong Kong, the Senior Fitness Test Manual was used as measures to establish normative data for older adults in Hong Kong and explore age and sex differences in functional fitness (Chung et al., 2016). Based on similar study's protocol (Chung et al., 2016), we also introduced the HG test which assess the strength of forearm. Participants are required to perform two trials on the gripping device (Takei Digital Grip Strength Dynamometer, Model T.K.K.5401) with maximum effort in a standing position with both arms beside the thighs. In all the tests, only the best score was taken down as the actual score. In order to ensure the tests were performed correctly, all participants had 1 practice trial or no more than 2 repetitions trial before the formal trial in each test. 
Appendix 2. Content of LVB intervention.

\begin{tabular}{|c|c|c|}
\hline Week & Topics & Activities \\
\hline 1. & $\begin{array}{l}\text { i. Programme introduction } \\
\text { ii. Pretest }\end{array}$ & $\begin{array}{l}\text { 1. Programme explanation } \\
\text { 2. Completing Questionnaire } \\
\text { 3. Warm-up and stretching } \\
\text { 4. Fitness test } \\
\text { 5. Cool-down and stretching }\end{array}$ \\
\hline 2. & $\begin{array}{l}\text { i. LVB overview } \\
\text { ii. History of LVB } \\
\text { iii. Ball sense activity } \\
\text { iv. Posture }\end{array}$ & $\begin{array}{l}\text { 1. Introducing LVB } \\
\text { 2. Basic preparation posture } \\
\text { 3. Basic passing techniques }\end{array}$ \\
\hline 3. & Underarm passing & $\begin{array}{l}\text { Revision of underarm pass } \\
\text { Underarm pass with footwork }\end{array}$ \\
\hline 4. & Service & $\begin{array}{l}\text { Revision of underarm pass } \\
\text { Type of service: } \\
\text { - Underarm service } \\
\text { - Overhead services } \\
\text { - Float service }\end{array}$ \\
\hline 5. & Overhead passing & $\begin{array}{l}\text { Overhead services } \\
\text { Drills combined with both underarm and overhead pass }\end{array}$ \\
\hline 6. & Spin service and spiking & $\begin{array}{l}\text { Revision of services } \\
\text { Introducing spin service } \\
\text { Spiking on spot } \\
\text { Spiking with movement } \\
\text { Spiking with net }\end{array}$ \\
\hline 7. & LVB unique move & $\begin{array}{l}\text { "Stick" } \\
\text { "Scoop" }\end{array}$ \\
\hline 8. & LVB unique move & $\begin{array}{l}\text { "Catch" } \\
\text { "Lift" }\end{array}$ \\
\hline 9. & Combing all unique moves in practices & $\begin{array}{l}\text { Revision of all types of unique move } \\
\text { Drills combing with all types of unique move in practice }\end{array}$ \\
\hline 10. & Blocking & $\begin{array}{l}\text { Revision of unique moves } \\
\text { Individual block } \\
\text { Team blocking }\end{array}$ \\
\hline 11. & Drop shot & Revision of blocking \\
\hline 12. & Introduction of LVB games & $\begin{array}{l}\text { Revision of spiking } \\
\text { Explain the rules and regulations of LVB }\end{array}$ \\
\hline $\begin{array}{l}13 . \\
14 .\end{array}$ & $\begin{array}{l}\text { LVB team tactics } \\
\text { LVB team tactics }\end{array}$ & $\begin{array}{l}\text { Attack and defense tactic } \\
\text { Attack and defense tactic }\end{array}$ \\
\hline 15. & Programme summary Posttest & $\begin{array}{l}\text { 1. Programme summary } \\
\text { 2. Completing Questionnaire } \\
\text { 3. Warm-up and stretching } \\
\text { 4. Fitness test } \\
\text { Cool-down and stretching }\end{array}$ \\
\hline
\end{tabular}




\section{The effects of light volleyball intervention programme in improving selected physical and psychological attributes of older adults in Hong Kong}

\section{Ka-Man Leung, Pak-Kwong Chung \& Martin S. Hagger}

To cite this article: Ka-Man Leung, Pak-Kwong Chung \& Martin S. Hagger (2018): The effects of light volleyball intervention programme in improving selected physical and psychological attributes of older adults in Hong Kong, International Journal of Sport and Exercise Psychology, DOI: 10.1080/1612197X.2018.1462231

To link to this article: https://doi.org/10.1080/1612197X.2018.1462231

Published online: 18 Apr 2018.

Submit your article to this journal एँ

Џll Article views: 10

Q View related articles $\square$

View Crossmark data 〔 